\title{
Study of Primitive and Reproducibility of Arts and Crafts
}

\author{
Hua He \\ Xiamen Academy of Fine Arts, Fuzhou University, Xiamen, China \\ aehehua2163.com
}

Keywords: Arts, Crafts; Primitive; Renewable

\begin{abstract}
People of all ethnic groups according to their actual needs as well as their understanding of beauty, to create different forms of arts and crafts, reflects the relationship between man and nature, showing the national culture and national wisdom. This article outlines the practical value and aesthetic value of arts and crafts, arts and crafts explains how to become a heritage of national customs carrier, for arts and crafts and regeneration of primordial parsing and propose how to make the Primitive Arts and regeneration in modern society.
\end{abstract}

\section{Introduction}

Arts and crafts are the history of human development is a bright pearl, with a very long history. The ancient tradition of agriculture and handicraft are the source of the original nature of arts and crafts. With the development of industrial technology, high technology and mechanical technology has gradually become another impetus to the development of industrial art. Arts and crafts works not only on the material to meet the needs of some people, but enrich people's spiritual life.

Arts and crafts can also be called handmade art, the original dynamic model of endogenous development from ancient handicraft and technical state of agriculture. The development of modern society comes from the development of the power mode state machinery industry and high-tech. Different power modes produce a different social composition and social way of life, resulting in different cultural values and different aesthetic needs, while also lays out people's eyes a different picture of the world.

Arts and Crafts are actually a people basic necessities including agricultural era of artistic creation. The first arts and crafts, daily necessities is handmade artwork is living, to the development and practical appreciation later Caifen into two categories, so its existence and manifestations, often by different lifestyles and different aesthetic Culture of the decision. That is, different cultures often determine its different constituent way manual art.

\section{Overview of Arts and Crafts}

Writers and artists in the creative process tends to follow your inner feelings, according to the aesthetic principles of art, we can say that their pursuit is purely spiritual pursuit. Only when these works and life of the items linked only have practical value, for example, only the artist's paintings hang in the hall above it only decorative value. The arts and crafts are different from this. Arts and Crafts began in the private sector, which doomed the arts and crafts not only have aesthetic value, as well as some practical value. We can say that the practical value of the initial creation of folk arts and crafts of the first in the aesthetic value, or between the two co-exist. Therefore, in the production process, people do not bother to imitate some of the commodity on the market that already exists, but rather a creation based on real-life needs. The creative process into the craftsmen understanding of life, with distinct characteristics, so that works both use value and aesthetic value.

Traditional arts and crafts works often can reflect the ethnic characteristics of the times, reflecting the people's pursuit of a better life and longing, reflecting the nation's lifestyle and spiritual realm. Therefore, we say that the tradition of ethnic arts and crafts custom carrier. Arts and crafts filled every corner of folk, ancestral worship, the size of the rally and many other important activities occasions, in each case has different characteristics, arts and crafts, arts and crafts of different nationalities in the 
same situation are not used same, these are ideas that reflect the characteristics of the various activities as well as between different ethnic groups to some extent, the aesthetic differences. Arts and Crafts was able to become a unique traditional culture, it is because people in the creative process of art is not to be bound by the so-called principle, but according to the actual needs of the people, adding their own insights and understanding of life will be free to play, has some natural form, show us the most essential things in life. From this perspective, arts and crafts and services in people's lives is not just a tool, it is a pure art.

\section{The Explanation of Arts and Crafts}

With the social and economic development, people's material living standards improve, people began to raise their living environment a higher demand. Arts and Crafts possess unique artistic characteristics gradually being respected, people began to use arts and crafts to decorate their living environment, meet their spiritual needs. Making arts and crafts typical of the material is not picky, mostly original ecological materials. Artisans can even dispose of items into a fine arts and crafts for people to use and enjoy. Various materials and various forms of arts and crafts materials so that each piece has its own characteristics, both simple and flexible. This art from generation to generation, but different generations, arts and crafts are drawn from life, and joined the creator of life unique insights. For example, we are familiar with Yi lacquer to be divided into many types, in addition to wood tires, tire angle, as well as leather tires, bamboo tires, different patterns, different characteristics. In addition to tires vary outside bottom paint colors, painted lines of color is not exactly the same, in general, are in relatively calm color tone, mostly with black paint, painted lines usually yellow, red-based, using various ways mosaic, painting and sculpture to create. In addition, there are many arts and crafts using some everywhere, but also relatively inexpensive grass, hemp, rattan and other materials, making the process simple, easy, work is not therefore the lack of any practical and aesthetic. Clearly, these are the arts and crafts factory cannot be imitated, unable mass out.

For thousands of years, people inherit and develop arts and crafts, arts and crafts creative ways and creative types are continuously enriched. In modern society, people of arts and crafts made higher requirements, arts and crafts can hope with each scene, with more pronounced and precise theme. It is believed that arts and crafts are not just a tool, but it should bring people rich visual impact, experience the traditional culture has to offer in arts and crafts. This requires people to be regenerated in the original nature of creation of arts and crafts on the preservation of traditional arts and crafts eco-friendly materials, on the basis of natural texture, adding some modern elements to make arts and crafts exhibits a more colorful effect. That is, the arts and crafts of renewable creation is not to abandon the original nature, but in the emphasis on natural materials and natural forms, while more detail by way of making the process more delicate works of art to express the people's emotions. At the same time retain the practicality of arts and crafts, according to the creators as well as people interested in the subject of the work requirement, adding more abundant element, multi-functional requirements to meet people for arts and crafts.

\section{The Method to Make Primitive Arts and Regeneration in Modern Society}

Although we have always emphasized that the traditional arts and cultural heritage continues, but we cannot ask people to become producers of arts and crafts, we cannot require the traditional artisan never engaged in this profession. Therefore, to arts and crafts will continue to carry forward this art, it is necessary to make a part of the family tradition of arts and crafts will be protected, so that this art is not lost heritage, and can be reproduced in future generations of innovation. Such family area can be set to cultural attractions, people can visit the arts and crafts of the production process, if you are interested, you can also hands-on production. By such a way that more people know of arts and crafts, so that this can survive and continue to develop the art in modern society. For example, in Korea's Joseon period, there are many Korean potters were forced to live in Japan, where they survive for generations to make pottery, but now is less about ten generations, much is fifteen generations. 
Although times are changing, but their skills are still generations, this tradition because they can get the local government to protect, reward and encouragement. Of course, in modern society, we cannot ask a lot of traditional crafts people still continue to engage in their previous occupation, but to protect a part of the traditional family is still very necessary. On the one hand these traditional skills, knowledge repository is a long-term accumulation of local culture, on the other hand, there is a tradition of craftsmanship make people remember from the culture and history of a place.

The world economy showed global development after the death of integration, not only between countries economic exchanges, cultural integration between countries also continues to deepen. In this form, we of course want to learn the essence of culture of other countries, but must not lose ourselves, for arts and culture in the traditional process of development must maintain a unique national style, while maintaining the original ecology of the premise again on the diversified development. It works to maintain a certain national character, reflecting the culture and identity of each nation, while adding elements of a new era, given its more powerful vitality, evokes the traditional ethnic and cultural memory.

Social life in the future, handmade art on the function of human life service, great changes will take place, and its function as a material service will be weakened, but its function was to strengthen the spirit of service. Because people just a creature of man, or of a spiritual, creative people. He hopes to meet the needs of not only physical, but also hope to have opportunities for self-development and self-expression. The craftsmanship is a huge space for self-development and self-expression. In fact, early humans, human development is complete, at which time everyone singing and dancing, everyone can engage in painting and handicraft work. It was only after the industrial civilization, developing highly specialized division of labor becomes unitary people. With further enrich and increase free time human material life, people will rebuild their spiritual home on the basis of the material wealth to rebuild their own artistic world. For modern people, the variety of arts and crafts and art work will not only be career artists and artists, but also everyone can participate also willing to participate in daily activities. Various amateur handmade arts activities and amateur artistic activities carried out, in fact, the future of humanity itself is the beginning of the revolutionary movement, a precursor to another emerging human revolution began.

In the new century, mankind will face not only from the physical aspects of the revolution, as well as from the spirit of human revolution, that is, human beings revolution. As for the white man to explore the potential of the body, the development of self-creativity, new understanding of man and man, man and the universe, the relationship between man and nature, as well as new understanding of their own cultural traditions and excavation, etc., so that the human a broader base of historical space and cultural knowledge, new understanding of our world, the idea of our cutting-edge science, the idea of our own humanity, and find a path to the future. On the contrary, if we abandon the road to move forward a lot of great cultural tradition behind them as a factor to be removed, so many peoples and nations have lost their original cultural force, then the future of human culture Development will be subject to various limitations, and lose a lot of new possibilities. From this perspective, the protection and development of traditional craftsmanship, it has very far-reaching significance, which retain excellent germplasm, there is the possibility of it in new renewable under the new historical background, it is very necessary.

\section{Conclusion}

Arts and Crafts began in the private sector, unlike other arts, and crafts often both practical value and aesthetic value. All peoples and regions use different arts and crafts activities in various occasions, reflecting the nation's values and aesthetics. Primitive Arts and Crafts emphasis on ecological materials, typical of the works is simple. With the improvement of people's living standards, people want to arts and crafts to more accurately reflect life theme. This requires Primitive Arts and regeneration of creation, more attention to detail, into the more rich and delicate feelings in the works to meet the requirements of the people. 


\section{References}

[1] R.Yin. Primitive and renewable environmental installation art, J. Nanjing Art Institute (Fine Arts \& Design), 2007 (03): 186-187.

[2] O.Zhang, Review and reflection primitive folk art research, J. Decoration Journal, 2013 (04): 129-136.

[3] Y.Liu. Any flower waist dragon sacrifice ritual music primordial and its renewable, J. Big Stage, 2010 (07): 43.

[4] L.S.Pan, The revival of arts and crafts, J. Decoration, 2014 (05): 30-34. 